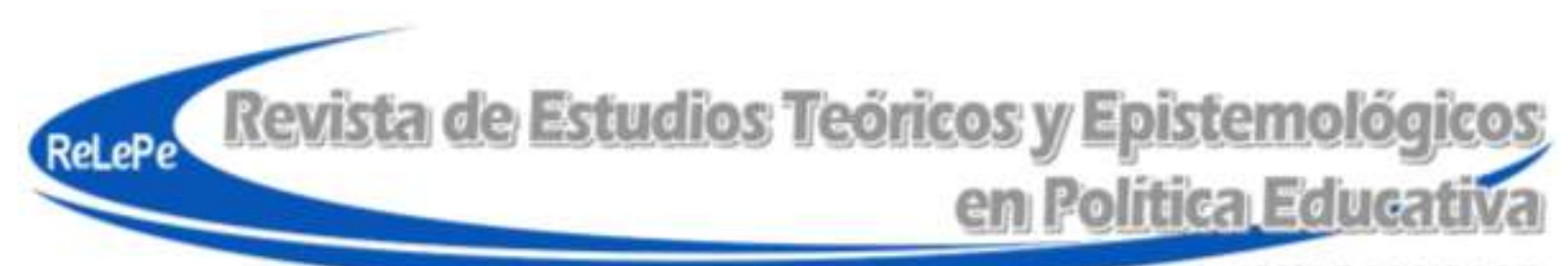

ISSN 2409-3696

do) https://doi.org/10.5212/retepe.v.7.20038.002

Resenha

\title{
LOTTA, Gabriela (org.). Teoria e análises sobre implementação de políticas públicas no Brasil. Brasília: ENAP, 2019. 324 p.
}

Alline do Carmo Barbosa Lemos* https://orcid.org/0000-0002-5047-3274

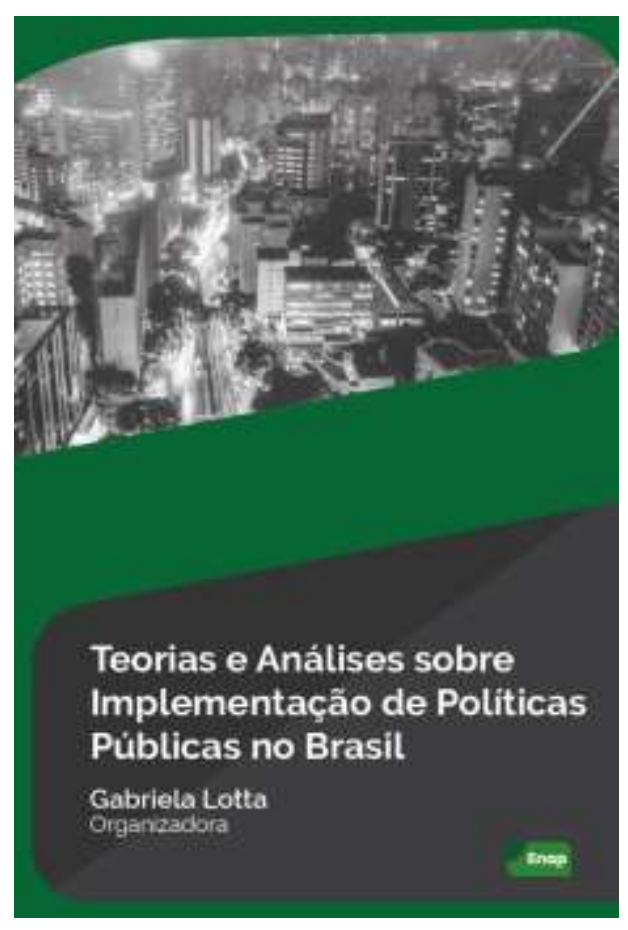

No contexto internacional, o campo de estudos sobre implementação de políticas públicas iniciou-se há, pelo menos, quatro décadas. Contudo, no Brasil, as pesquisas acerca desse assunto desenvolveram-se somente a partir dos anos de 2010. Ao longo do processo de fortalecimento desse campo, é importante destacar que muitos pesquisadores têm sido diligentes em colaborar com estudos de natureza teórica e empírica, abordando distintos objetos e recortes analíticos de políticas implementadas nos mais diversos âmbitos. Nesse sentido, a obra Teoria e análises sobre implementação de políticas públicas no Brasil, de Gabriela Lotta, resultado do empenho de estudiosos brasileiros dedicados à continuidade de pesquisas concernentes à implementação de políticas públicas, faz jus às considerações que aqui serão elaboradas a seu respeito (LOT'TA, 2019).

A publicação desse livro decorre de discussões suscitadas em 2018, no I Seminário Nacional de Estudos sobre Políticas Públicas, evento organizado pela Escola Nacional de Administração Pública (Enap), pela Universidade Federal do ABC (UFABC) e pela Pontifícia Universidade Católica do Rio de Janeiro (PUC-Rio), cuja realização simboliza uma referência significativa no progresso de investigação dessa área do conhecimento. Além disso, nessa obra organizada por Lotta, é apresentado, de forma exordial, um panorama das pesquisas produzidas no âmbito da implementação de políticas públicas no Brasil, alguns dos principais pesquisadores responsáveis pelos estudos do campo, bem como as suas contribuições, metodologias e áreas de atuação (LOTTA, 2019).

Quanto à estrutura, o livro é constituído por prefácio e dez capítulos, cada qual redigido

\footnotetext{
* Doutoranda do Programa de Pós-Graduação em Educação (PPGE) da Universidade Estácio de Sá (Unesa), na linha de pesquisa Políticas, Gestão e Formação de Educadores (PGFE) e sob a orientação da Professora Doutora Laélia Portela Moreira. E-mail: <allinecblemos@yahoo.com.br>.
} 
por diferentes autores. Iniciando as reflexões acerca dos estudos de implementação, Gabriela Lotta, no primeiro capítulo, trata da temática em questão ao situar espacial e temporalmente a literatura acerca dos estudos de implementação de políticas públicas, além de apresentar, por meio de recortes teóricos, metodológicos e temáticos, os pressupostos e os objetos analíticos que auxiliam no aprimoramento das investigações relacionadas à implementação. Em seu texto, a autora expõe aspectos que subsidiam o desenvolvimento dessas investigações, evidencia que a literatura dessa área tem progredido e que a sua aplicação representa um benefício para os estudos de políticas públicas em geral. Lotta ainda declara que o grande objetivo desse campo é examinar de que forma os serviços públicos adquirem uma existência material por meio das ações dos burocratas, os quais transformam uma representação abstrata (geral) em algo concreto (específico).

Em seguida, no segundo capítulo, Sandra Gomes explora o debate acerca de uma agenda coletiva de investigação por meio da construção e da análise de pesquisas que integrem, a despeito dos vieses distintos, as perspectivas analíticas top-down (esfera macro) e bottom-up (esfera micro) como forma de melhor compreender o processo de implementação, delinear uma formulação institucional mais adequada, ampliar o conhecimento acerca dos aspectos que afetam o resultado de determinada política e gerar debates acerca da necessidade de uma visão reparadora das desigualdades reproduzidas nos processos de implementação utilizados.

Diferentemente da maioria dos estudos que se concentram na estrutura do jogo político (polity) para elucidar os resultados alcançados pelo processo de implementação das políticas públicas (policies), no terceiro capítulo, Vanessa Elias de Oliveira e Cláudio Gonçalves Couto percorrem o caminho inverso ao proporem o modelo de análise de diretrizes prioritárias que orientam a implementação das políticas públicas. Ao partirem da perspectiva das políticas públicas, de seu processo de implementação e dos reveses dele decorrentes, Oliveira e Couto têm a finalidade de elucidar as decisões institucionais que determinam, posteriormente, o jogo político. Os autores argumentam ainda que as diretrizes prioritárias são as responsáveis por conduzir as políticas públicas e que os problemas decorrentes da etapa da implementação definem os mecanismos institucionais necessários à colaboração entre os entes governamentais.

Na sequência, no quarto capítulo, Peter Kevin Spink e Fernando Burgos analisam os limites do pressuposto gerado pela narrativa da racionalidade instrumental de que a implementação segue do geral para o específico e examinam criticamente os estudos do campo sugerindo uma perspectiva que permita perceber as fragilidades institucionais ocasionadas pela própria política pública.

A seguir, é no quinto capítulo que se encontram as considerações de Luciana Leite Lima e Luciano D'Ascenzi, os quais examinam as diversas concepções e funções dos objetivos nos processos de implementação, de modo a elucidar e discutir aspectos importantes na relação entre essa etapa e a avaliação, além de explorarem a maneira com que os modelos analíticos de implementação abordam a relação estabelecida entre os objetivos formulados e a execução. Outrossim, os autores propõem um método de avaliação e de articulação das políticas públicas cujo critério se baseia na habilidade de produzir impacto em termos de desenvolvimento e de modificação da realidade social.

Para além de apenas entender a função da burocracia e o seu efeito nas políticas de implementação, o sexto capítulo, sob a autoria coletiva de Natália Massaco Koga, Rafael Rocha Viana, Marizaura Reis de Souza Camões e Fernando de Barros Gontijo Filgueiras, apresenta um estudo voltado para a compreensão dos servidores públicos brasileiros com base em aspectos relacionados ao perfil, à trajetória, à percepção e à atuação dos burocratas (com particular atenção àqueles que desempenham suas funções na administração pública federal direta) no processo de implementação das políticas. Com base nessa investigação, os autores proporcionam ao leitor um 
panorama amplo das dimensões que envolvem o serviço público federal, assim como a análise das capacidades dos servidores, de como elas estão distribuídas no trabalho por eles desempenhado e de como isso é considerado na gestão desse serviço.

Importa salientar que, do sétimo capítulo em diante, ocorre uma mudança no modo como o assunto da implementação é tratado pelos autores do livro, pois, enquanto os capítulos anteriores nitidamente apresentaram reflexões acerca da implementação de políticas privilegiando mais a sua vertente conceitual e teórica, a partir de então, os textos subsequentes enfocarão o processo de implementação, baseando-se em políticas públicas bem específicas.

A pesquisa apresentada por Alicia Bonamino, Maria Océlia Mota, Maria Elizabete Neves Ramos e Erisson Viana Correa, no sétimo capítulo, propõe a análise do arranjo institucional e da forma de implementação do Programa de Aprendizagem na Idade Certa (Paic). O estudo apresenta dois objetivos principais: a) investigar a configuração institucional e organizacional do Paic com o intuito de compreender a sua capacidade de oferecer parâmetros para o cumprimento dos objetivos pretendidos; e b) perceber como essa organização institucional articula o Burocrata de Médio Escalão (BME), aqui representado pelo Gerente Municipal (GM), à implementação do Programa.

Em seguida, Renata Bichir, Sergio Simoni Júnior e Guilherme Pereira, responsáveis pela composição do oitavo capítulo, analisam o sistema nacional de políticas públicas, caracterizado pelo arranjo federativo dos anos de 1990, visando a compreender as suas implicações no processo de implementação dos benefícios socioassistenciais do Sistema Único de Assistência Social (SUAS) nos municípios brasileiros. Nesse sentido, os autores examinam o poder das normativas de regulamentação do SUAS em promover efeitos de indução local, isto é, reduzir as disparidades territoriais, suscitar o desenvolvimento da implementação e viabilizar a equiparação no oferecimento de serviços de proteção básica, ponto central deste artigo.

Semelhantemente ao estudo anterior, o nono capítulo também se dedica à análise do SUAS, porém com o foco em uma de suas políticas, a Proteção e Atendimento Integral à Família (Paif), serviço socioassistencial oferecido de forma obrigatória pelos Centros de Referência de Assistência Social (Cras) em áreas com maior vulnerabilidade e/ou risco social e que se relaciona a dois aspectos estruturantes da Política Nacional de Assistência Social (Pnas): a centralidade na família e no território. Nesse trabalho, a socióloga Luciana Jaccoud investiga em que medida o SUAS, a partir do Paif, proporciona benefícios e serviços ao atuar na coordenação intergovernamental dos territórios, uma vez que tal ação assim como os contextos e atores inerentes ao processo de implementação são, por excelência, constituídos por um alto nível de complexidade. Entre tantas constatações apontadas pela autora, destacamos a que se refere aos dados empíricos explorados nessa pesquisa, os quais ratificam que os instrumentos de coordenação limitam a autonomia dos governos locais no que tange à discricionariedade acerca da política implementada.

Finalizando a exposição dos trabalhos, Mani Tebet Marins, autora do décimo capítulo, volta-se para uma política específica e que, como as mencionadas anteriores, ocupa um espaço fulcral no campo da assistência social: o Programa Bolsa Família (PBF). Valendo-se do conceito de governamentalidade, a pesquisadora investiga de que maneira são forjadas consequências não previstas (violência simbólica) a partir da implementação do PBF, tais como estigmatização política, moral e simbólica, refletindo, assim, como são constituídas concepções de classe, de gênero e de ordem familiar, no cerne das políticas de transferência de renda, como é o caso do PBF.

Diante de todos os aportes teóricos e metodológicos aqui apresentados, bem como as profundas contribuições para o campo dos estudos de implementação de políticas públicas expostas, podemos assegurar que a obra Teoria e análises sobre implementação de políticas públicas no Brasil é notável e, portanto, altamente recomendável não somente para os especialistas da área, mas 
também àqueles que se interessam por questões atinentes aos contextos políticos, econômicos e sociais do país. Ademais, essa publicação põe luz sobre um tema ainda incipiente no contexto brasileiro e aproxima pesquisadores principiantes interessados em compreender a complexidade do processo de implementação.

\section{Referência}

LOTTA, G. (org.). Teoria e análises sobre implementação de políticas públicas no Brasil. Brasília: $\quad 2019 . \quad$ DNAP, Disponível em: https://repositorio.enap.gov.br/bitstream/1/4162/1/Livro Teorias $\% 20 \mathrm{e} \% 20 \mathrm{An} \% \mathrm{C} 3 \% \mathrm{~A} 1$ lises $\% 20$ sobre $\% 20$ Implementa $\% \mathrm{C} 3 \% \mathrm{~A} 7 \% \mathrm{C} 3 \% \mathrm{~A} 3 \mathrm{O} \% 20 \mathrm{de} \% 20 \mathrm{Pol} \% \mathrm{C} 3 \% \mathrm{ADticas} \% 20 \mathrm{P} \% \mathrm{C} 3 \% \mathrm{BAbli}$ cas $\% 20$ no $\% 20$ Brasil.pdf. Acesso em: 20 jan. 2022. 